\title{
Links between nutrition, life style habits and academic achievement in Palestinian schoolchildren: A cross-sectional study
}

RESEARCH

\section{Radwan Qasrawi 1,*, Diala Abu AL Halawa1,", Rawan Ayyad1, Halema AL Sabah², Haneen Taweel ", and Ziad Abdeen ${ }^{3}$}

1 Department of Computer Science, Al-Quds University, Jerusalem, Palestine.

${ }^{2}$ College of Natural and Health Sciences, Zayed University, United Arab Emirates

${ }^{3}$ Al-Quds Public Health Society, Jerusalem, Palestine

\section{A B S T R A C T}

Objective: To examine the association between nutrition, physical activity, lifestyle, the combined behavior effect, and the schoolchildren's academic achievement. Design: Observational and cross-sectional study. Setting: West Bank, Palestine. Participants: A group of schoolchildren ( $n=1945)$ in grades 5-9 (11-16 years). Measurements: Students were surveyed about the their 'dietary, physical activity (PA), leisure time activity, and academic achievement. Academic achievement was measured using students' marks in Arabic, English, math, science courses, and the total average score. The linear regression model was conducted to analyze the relationship between dietary, PA, combined behavior, and academic achievement, while adjusted for demographic confounders; body mass index (BMI), and parental education. Results: Findings indicated that healthy nutrition and adequate levels of PA significantly predict achievement scores. In both boys and girls, high academic achievement was associated with a high intake of fruits and vegetables (AOR: 1.1 (0.72-1.68); 1.18(0.81-1.7), and (AOR: 1.21(0.8-1.82); 1.33(0.93-1.91), respectively. In both girls and boys, high academic achievement was associated with low intake of soft drink, beverages (juice with sugar) and energy drink (AOR: (0.75(0.47-1.19), 0.85(0.58-1.27)); (0.99(0.63-1.57), 0.76(0.52-1.12)); (0.66(0.38-1.15), 0.49(0.27-0.89)), respectively. The active and healthy nutrition group scored higher on Arabic, English, math, science, and total average score. Conclusions: There is a strong relationship between healthy nutrition, acceptable PA, and the average academic achievement within schoolchildren. Findings emphasize the importance of linking nutrition, school PA, and health policies for improving cognitive functions and academic performance of Palestinian schoolchildren. Thus, school-based healthy lifestyle educational, health behaviors policy, and recommendation programs may have a greater effect on students' academic achievement.

Keywords: Nutrition, physical activity, academic achievement, schoolchildren, linear regression

\section{Introduction}

The effect of nutrition and health on academic performance has been approved by many research studies. Good health, nutrition, and physical activity improve cognitive functions among students and lead to better academic

\footnotetext{
* Correspondence:

Department of Computer Science, Al-Quds University, Jerusalem, Palestine.

E-mail: radwan@staff.alquds.edu

Tel: +972592660417

(c) copy rights 2021: All materials in this article are protected. permission requests should be addressed to Al-Quds University. www. alquds.edu
}

performance, particularly in school years it is linked to higher levels of future wealth and health (Pavleski, Koltovska-Nechoska, and Ivanjko 2017; Burkhalter and Hillman 2011; Janssen 2012; Forrest et al. 2013; Kristo et al. 2020). Various modifiable factors influence academic achievement, including socioeconomic status, nutrition,physical activity, and social wellbeing, which affect individual and community growth from birth through adolescence (Faught et al. 2017; Adolphus, Lawton, and Dye 2013; S. Y. Kim et 
al. 2016; Montazerifar, Karajibani, and Dashipour 2012; Stea and Torstveit 2014; Vadiveloo, Zhu, and Quatromoni 2009; Taras 2005; Dubuc, AubertinLeheudre, and Karelis 2020). Various studies have investigated the association between different nutritional aspects and academic achievement (Banerjee 2016; Marques et al. 2017; Bleiweisssande et al., 2019; Stea and Torstveit 2014). Healthy nutritional practices such as breakfast intake were investigated and found to be significantly associated with better academic attainment (Alhilabi and Payne 2018; Jeong 2019; Lundqvist and Vogel 2019). Moreover, diet quality has been linked to differences in academic achievement. Studies show that healthy food intake, including fruits, vegetables, grains, legumes and milk, and a lower intake of energy-rich, poor nutrient food groups (e.g. junk/fast food) are correlated with academic outcomes (Burrows et al. 2017; Asmare et al. 2018). Nutrient analysis including macro and micronutrients among different food groups was also studied to gain an indepth analysis of adequacy and diversity of nutrient intake. For example, many studies report a positive effect of folate, iron, and $B$ group vitamins, which may have different food sources, on academic achievement (Burrows et al. 2017). Physical activity is also an important determinant of educational attainment. Several studies demonstrate that higher marks are found in students who have regular physical activity, characterized by moderate- to vigorous-intensity physical activity daily (Castelli et al. 2015; Cook and Board 2013). Moreover, interventions to integrate physical education classes in schools have shown better academic outcomes (Castelli et al. 2015). Another important health indicator is obesity. It has been demonstrated in the literature that obesity, as an independent factor, correlates with poorer mental function and academic outcomes (Asigbee et al., 2018). The above associations were mostly studied individually. Few studies have investigated the interdependence between various variables and academic achievement (Hou et al. 2020; Florence et al., 2008; Castelli et al. 2015;
Marques et al. 2017). In Palestine, there is a shortage in nationwide studies that examine the relationship between the above-mentioned variables and academic achievement. One study in the Gaza strip showed that the intake of fruit and vegetables was positively associated with school performance among adolescents in Gaza Strip while stunting was negatively associated with school performance (Abudayya et al. 2011). However, there is a need for an indepth investigation of the dietary patterns prevailing in Palestine. Moreover, up to our knowledge, there's no study of the correlation between multiple health determinants and academic achievement. Therefore, this study aims to investigate the individual and combined behaviors effect of nutrition, physical activity, and obesity on academic achievement among primary and secondary school children in the West Bank, Palestine, in an attempt to make recommendations on the possible interventions using the above-mentioned factors, thereby enhancing academic performance.

\section{Methods}

\section{Sample Population}

Data were obtained from the national survey conducted in West Bank as a part of the Health Behavior in School-aged Children (HBSC) survey in 2013-2014. The study assessed the nutrition, physical and mental health of Palestinian schoolchildren in grades 5-9 (11-16 years).

A random sample of 2000 students were selected from the baseline database weighted for sex and grades. Out of 2000 students, 1945 students have accomplished the study criteria, the 55 students had missing data variables.

\section{Measure}

The survey used themodified Health Behavior in School-aged Children (HBSC) questionnaire (Roberts et al. 2007). The questionnaire contained questions about dietary intake, physical activity, leisure time activity, anthropometric measurements (height, weight, waist, and neck 
circumstance), and academic achievement. Physical activity: Two scales were used to measure physical activity levels.The activity scale composed of three items: (1) For the last week, how many days were you physically active for more than 60 minutes, (2) number of hours playing sports outside school, (3) number of hours exercising per week. The second scale was used to measure the leisure time activity level. The scale items include (1) number of hours watching TV, (2) number of hours playing video games, and (3) number of hours using the internet. The 6 items asked for weekday and excluded the weekends. Based on the sum of the items, the respondents were analyzed using quartiles for both scales. The activity scale used the upper quartiles for identifying the physically active students, and the upper quartiles in the leisure time activity scale were used to identify the low and non-active students.

Diet: Dietary intake information was collected using face to face 24-hour food recall of one day intake and the food frequency questionnaire (FFQ). The food frequency scale was developed using the 8 food items scale. The food items were grouped into 8 categories based on similarity in nutrient profile (Frank et al. 1992).

These categories were: 1) vegetables; 2) fruits; 3) milk and other dairy products; 4) sweets and chocolate; 5) soft drinks; 7) beverages (juices and sugar); 8) energy drinks. Response categories were (1) never, (2) 1-2 times a week, (3) 3-4 times a week, and (4) 5-7 times a week (almost daily). Students were categorized into two consumption groups, healthy and unhealthy consumers. The scale sum was used to form the two groups. The healthy group include participants who were in the top 2 quartiles and had indicated that they did not eat any unhealthy items (soft drinks, chocolates, or energy drinks), and the unhealthy group include participants who had indicated they did not eat any of healthy nutrition items (vegetables, fruits, milk, and milk products) and were in the top 2 quartiles of the frequency of eating unhealthy foods. Academic achievement: The students' marks were obtained from the schools' marks records, the scores of all courses, and the total average score were obtained. In this study, we included the four major courses (Arabic Language, English language, math, and science) in addition to the total average score. Academic achievement was categorized into high and low scores. The grades higher than the mean were categorized as high, and grades lower than the mean were considered as low.

\section{Statistical analysis}

The statistical analysis was conducted using the IBM Statistical Package for Social Science V21. Physical activity, dietary consumption, and academic achievement were analyzed for describing the participants' characteristics. Oneway analysis of variance (ANOVA) was used to test for significant differences in lifestyle behaviors, food consumption, and academic achievements. Univariable logistic regression was first used to assess the associations between students' lifestyle behaviors, and their academic achievement. Next, multivariable models were used to adjust for potential confounders and body weight status. All lifestyle behaviors were considered in a full model to assess independent associations between meeting each lifestyle behavior, body weight status, food group consumptions, and academic achievement.

Finally, a series of linear regression analyses were used to examine the difference between the selected courses (Arabic language, English language, math, science, and the total score), physical activity, and nutrition.

All tests were controlled by SES, age, and sex. Also, the effect of the interaction between nutrition and physical activity on academic scores were examined by the linear regression analysis.

\section{Results}

A descriptive analysis of study participants indicated that students from grade 5-9(11-16years) were selected. The distribution by gender was 
47.3\% boys and $52.7 \%$ girls. The student's sample was $55.1 \%$ from public schools and $\sim 45 \%$ from UNRWA (Refugee schools). In regards to parent's education, $66 \%$ of fathers had less than 12 years of education and $34 \%$ had more than 12 years of education. An almost similar trend was found for the mother's education. Parents' education level was very similar between boys and girls. More than half of the students had moderate family economic status (55.1\%), while $34.7 \%$ and $10.2 \%$ had low and high economic status respectively. Students' lifestyle characteristics including physical activity, healthy food consumption, smoking, and BMI are given in table 1. The majority of students found to be physically active in all ages, only $17.1 \%$ of students had reported a low level of physical activity. However, more girls had a moderate activity level than boys (60.3\%, 52.2\%), and boys had higher activity level than girls $(38.2 \%, 16 \%)$, respectively. About $43 \%$ of students spent $1-2 \mathrm{~h} /$ day in leisure time activity, while more girls spent $<1 \mathrm{~h} /$ day than boys (35.9\%, 27.8\%) respectively, and more boys spent $>3 \mathrm{~h} /$ day than girls (29.1\%, 20.5\%), respectively. About $10 \%$ of students were smoking cigarettes or Nargila, and a higher prevalence of smoking was found in boys. The BMI results showed that $5.5 \%$ of students underweight, $9.7 \%$ were overweight and $4.2 \%$ obese. Higher prevalence of overweight and obesity rates was found in girls.

Table 2 presents the relation between academic achievement and the students' intake from different food groups. The high academic achievement group reported higher fruits and vegetable consumption than lower academic achievement groups. On the other hand, the low academic achievement group reported higher soft drink and energy drink consumption.

The adjusted odds ratio (AOR) analysis showed increased odds of high academic achievement in boys and girls who had higher fruits consumption (AOR: 1.1 (0.72-1.68); 1.18(0.811.7), respectively, and boys and girls who had higher vegetable consumption (AOR:1.21(0.81.82); 1.33(0.93-1.91), respectively. Furthermore, the adjusted analysis indicated a decreased odds in boys and girls of high academic achievement with lower intake of soft drink, beverages (juice with sugar) and energy drink (AOR: 0.79(0.5$1.23) ; \quad 0.85(0.58-1.27)) ; \quad(0.99(0.63-1.57) ; 0.76(0.52-$ 1.12));(0.66(0.38-1.15),0.49(0.27-0.89)); respectively. Girls reported a higher intake of sweets and

Table 1: Lifestyle characteristics of schoolchildren by gender.

\begin{tabular}{|c|c|c|c|c|}
\hline Characteristics & Category & $\operatorname{Boys}(n=920)$ & $\begin{array}{c}\text { Girls(n=1025) } \\
n(\%)\end{array}$ & Total \\
\hline \multirow[t]{3}{*}{ Physical activity } & Low activity & $89(9.7)$ & $243(23.7)$ & $332(17.1)$ \\
\hline & Moderate Activity & $480(52.2)$ & $618(60.3)$ & $1098(56.5)$ \\
\hline & High activity & $351(38.2)$ & $164(16)$ & $515(26.5)$ \\
\hline \multirow[t]{3}{*}{ Leisure time activity } & $<1$ hour/day & $256(27.8)$ & $368(35.9)$ & $624(32.1)$ \\
\hline & 1-2hours/day & $396(43)$ & $447(43.6)$ & $843(43.3)$ \\
\hline & $>3$ hour/day & $268(29.1)$ & $210(20.5)$ & $478(24.6)$ \\
\hline \multirow[t]{2}{*}{ Healthy Food Consumption } & Poor & $508(55.2)$ & $522(50.9)$ & $1030(53)$ \\
\hline & Good & $412(44.8)$ & $503(49.1)$ & $915(47)$ \\
\hline \multirow[t]{2}{*}{ Smoking } & Yes & $135(14.7)$ & $56(5.5)$ & $191(9.8)$ \\
\hline & No & $785(85.3)$ & $969(94.5)$ & $1754(90.2)$ \\
\hline \multirow[t]{4}{*}{ BMI } & Underweight & $62(6.7)$ & $45(4.4)$ & $107(5.5)$ \\
\hline & Normal & $764(83)$ & $804(78.4)$ & 1568(80.6) \\
\hline & Overweight & $66(7.2)$ & $122(11.9)$ & $188(9.7)$ \\
\hline & Obese & $28(3)$ & $54(5.3)$ & $82(4.2)$ \\
\hline
\end{tabular}


chocolates than boys. The adjusted analysis showed increased odds of high academic achievements in girls and decreased odds in boys who had sweet and chocolate intake. Table 3 presents the physical activity and leisure time activity levels relative to academic achievement. The adjusted analysis showed increased odds of high academic achievement in boys and girls who had high physical activity (AOR: 1.2(0.7-2.1); 1.5(0.9-2.6)), respectively. In addition, results showed increased odds of high academic achievement in boys and girls who had high leisure-time activity, and girls reported higher value than boys, (AOR: 1.3 (0.8-2.0); 1.4 (0.9-2.2), respectively.
Table 4 presents the mean and standard deviation of marks for all groups. The mean marks for all subjects (Arabic, English, math and science) were higher in group 1 (healthy, active, and healthy and active groups) than students in group 2 (unhealthy, non-active, unhealthy and non-active, and overweight and obese groups). Significant differences were found between the two groups.

The linear regression was used to predict the effect of healthy nutrition and physical activity on Arabic, English, math and science achievement scores, controlled by age, sex, parent education, and SES, which is presented in table 5 and 6 The results of linear regression for Arabic language score indicated that healthy

Table 2: Adjusted odds ratio (AOR) and $95 \% \mathrm{Cl}$ for academic achievement in relation to the intake of healthy and unhealthy food items in girls and boys.

\begin{tabular}{|c|c|c|c|c|c|c|}
\hline & \multicolumn{3}{|c|}{ Boys $(n=920)$} & \multicolumn{3}{|c|}{ Girls $(n=1025)$} \\
\hline & $\begin{array}{l}\text { Low academic } \\
\text { Achievement } \\
(\mathrm{n} \%)\end{array}$ & $\begin{array}{l}\text { High academic } \\
\text { Achievement }\end{array}$ & $\mathrm{AOR}(++)$ & $\begin{array}{l}\text { Low academic } \\
\text { Achievement }\end{array}$ & $\begin{array}{l}\text { High academic } \\
\text { Achievement(n\%) }\end{array}$ & $\mathrm{AOR}(++)$ \\
\hline Fruits & $215(44.2)$ & $224(51.6)$ & $1.1(0.72-1.68)$ & $237(49.3)$ & $288(52.9)$ & $1.18(0.81-1.7)$ \\
\hline Vegetables & $229(47.1)$ & $230(53)$ & $1.21(0.8-1.82)$ & $236(49.1)$ & $327(60.1)$ & $1.33(0.93-1.91)$ \\
\hline $\begin{array}{l}\text { Milk \& Milk } \\
\text { Products }\end{array}$ & $210(43.2)$ & $188(43.3)$ & $0.88(0.58-1.34)$ & $172(35.8)$ & 212(39) & $0.93(0.64-1.36)$ \\
\hline $\begin{array}{l}\text { Sweets \& Choc- } \\
\text { olates }\end{array}$ & $142(29.2)$ & $125(28.8)$ & $0.75(0.47-1.19)$ & $164(34.1)$ & $195(35.8)$ & $1.41(0.96-2.06)$ \\
\hline Soft Drinks & $193(39.7)$ & $164(37.8)$ & $0.79(0.5-1.23)$ & $173(36)$ & $169(31.1)$ & $0.85(0.58-1.27)$ \\
\hline $\begin{array}{l}\text { Beverages (juice } \\
\text { with sugar) }\end{array}$ & $159(32.7)$ & $159(36.6)$ & $0.99(0.63-1.57)$ & $178(37)$ & $182(33.5)$ & $0.76(0.52-1.12)$ \\
\hline Energy Drinks & $108(22.2)$ & $66(15.2)$ & $0.66(0.38-1.15)$ & $57(11.9)$ & $31(5.7)$ & $0.49(0.27-0.89)$ \\
\hline
\end{tabular}

++Adjusted for BMI, SES and paternal education

Table 3: Adjusted odds ratio (AOR) and 95\% $\mathrm{Cl}$ for high academic achievement in relation to physical activity and leisure time activity by sex.

\begin{tabular}{|c|c|c|c|c|c|c|}
\hline & \multicolumn{2}{|c|}{ Boys $(n=920)$} & \multirow[b]{2}{*}{$\mathrm{AOR}(++)$} & \multicolumn{2}{|c|}{ Girls(n=1025) } & \multirow[b]{2}{*}{$\mathrm{AOR}(++)$} \\
\hline & $\begin{array}{l}\text { Low academ- } \\
\text { ic Achieve- } \\
\text { ment(n\%) }\end{array}$ & $\begin{array}{l}\text { High academic } \\
\text { Achievement }\end{array}$ & & $\begin{array}{l}\text { Low academic } \\
\text { Achievement }\end{array}$ & $\begin{array}{c}\text { High academic } \\
\text { Achievement(n\%) }\end{array}$ & \\
\hline $\begin{array}{l}\text { High physical } \\
\text { activity }\end{array}$ & $309(63.5)$ & $306(70.5)$ & $1.2(0.7-2.1)$ & $210(43.6)$ & $231(42.5)$ & $1.5(0.9-2.6)$ \\
\hline $\begin{array}{l}\text { High Leisure } \\
\text { time activity }\end{array}$ & $161(33)$ & 13731.6(31.6) & $1.3(0.8-2.0)$ & $117(24.3)$ & 104(19.1) & $1.4(0.9-2.2)$ \\
\hline
\end{tabular}

${ }^{+}$Adjusted for BMI, SES and paternal education 
intake, physical activity, and their interaction were significant predictors of Arabic language score $(F(6,1938)=19.9, p<.01)$, with an R2 of 0.058 . Healthy intake, physical activity, healthy intake and physical activity, SES, age and sex were significant predictors of Arabic score $(\mathrm{HI}, \mathrm{t}=2.8$ $p<0.01, \mathrm{PA}, \mathrm{t}=3.2, p<0.01[\mathrm{HI} \times \mathrm{PA}], \mathrm{t}=2.5, p<0.05$, SES, $\mathrm{t}=5.9, \mathrm{p}<0.01$, age, $\mathrm{t}=-5.6, p<0.01$, sex, $\mathrm{t}=4.2$, $p<0.01)$. In addition, the prediction equation for Arabic score (YArabic $=60.1+3.3 \mathrm{HI}+1.5 \mathrm{PA}+4.5$ [HIXPA] +3.6SES-2.8age+3.3sex) indicates the folowing for significant predictors: (1) As healthy intake increased by one unit, the Arabic score increased by 3.3 , (2) as physical activity increased by 1 unit, the Arabic score increased by 1.5, (3) as the interaction between healthy intake and physical activity increased by 1 unit the Arabic score increased by 4.5, (4) as the SES increased by 1 unit, the Arabic score increased by 3.6 (5) as age increased by 1 unit, the Arabic score decreased by 2.8 (6) the sex influenced the Arabic score with girls scoring higher by 3.3 than boys.

The results of linear regression for English language score indicated that healthy intake, physical activity, and their interaction were significant predictors of English score $(F(6,1938)$ $=18.6, p<.01$ ), with an R2 of 0.054 .

The healthy intake, physical activity, healthy intake and physical activity, SES, age and sex were significant predictors of English score $(\mathrm{HI}, \mathrm{t}=2.6$ $p<0.01, \mathrm{PA}, \mathrm{t}=3.3, p<0.01,[\mathrm{HI} \times \mathrm{PA}], \mathrm{t}=2.2, p<0.05$,
SES, $\mathrm{t}=5.9, p<0.01$, Age, $\mathrm{t}=-5.3, p<0.01$, Sex, $\mathrm{t}=3.8$, $p<0.01)$. In addition, the prediction equation for English language score ( $Y$ English $=55.4+3.3 \mathrm{HI}+1$. 7PA+4.2 [HIXPA]+3.9SES-2.9age+3.2sex) indicates the following for significant predictors: (1) As healthy intake increased by one unit, the English score increased by 3.3, (2) as physical activity increased by 1 unit, the English score increased by 1.7, (3) as the interaction between healthy intake and physical activity increased by 1 unit the English score increased by 4.2, (4) as the SES increased by 1 unit, the English score increased by 3.9 (5) as age increased by 1 unit, the English score decreased by 2.9 (6) sex influenced the English score with girls scoring higher by 3.2 than boys. The results of linear regression for math score indicated that healthy intake, physical activity, and their interaction were significant predictors of math score $(F(6,1938)=13.3, p<.01)$, with an R2 of 0.038 . The healthy intake, physical activity, SES, and age were significant predictors of math score. $(\mathrm{HI}, \mathrm{t}=1.7 p<0.05$, PA, $\mathrm{t}=2.8$, $p<0.05$, SES, $\mathrm{t}=5.8, p<0.01$, Age, $\mathrm{t}=-5.5, p<0.01)$. In addition, the prediction equation for math score (Ymath=58.7+2.2HI+1.4PA+3.9SES-3age $)$ indicates the following for significant predictors:

(1) As healthy intake increased by one unit, the math score increased by 2.2, (2) as physical activity increased by 1 unit, the math score increased by 1.4 , (3) as the SES increased by 1 unit, the math score increased by 3.9 (4) as age increased by 1

\begin{tabular}{llllll}
\hline & Arabic & English & Math & Science & $\begin{array}{l}\text { Total Av. } \\
\text { Score }\end{array}$ \\
\hline Healthy intake & $74.1 \pm 16.9^{* *}$ & $70 \pm 19^{* *}$ & $67.3 \pm 18.4^{*}$ & $72.5 \pm 18$ ** & $75.9 \pm 13.1$ \\
Unhealthy intake & $70.8 \pm 17.7 *$ & $66 \pm 19^{*}$ & $64.9 \pm 18.7^{*}$ & $68.9 \pm 18.5^{*}$ & $73.7 \pm 12.9$ \\
Active & $73.7 \pm 16.8^{*}$ & $69 \pm 18$ & $67.6 \pm 18^{*}$ & $72.3 \pm 17.1^{*}$ & $75.3 \pm 13.1$ \\
Non-Active & $71.9 \pm 17.5^{*}$ & $67 \pm 19$ & $65.5 \pm 18.7^{*}$ & $70 \pm 18.1 *$ & $73 \pm 13.1$ \\
Healthy \& Active & $74.4 \pm 17 *$ & $70 \pm 18^{*}$ & $68 \pm 18.4$ & $73.6 \pm 17.1^{*}$ & $73.6 \pm 13.1$ \\
$\begin{array}{l}\text { Unhealthy \& non } \\
\text { Active }\end{array}$ & $70 \pm 18 *$ & $66 \pm 19 *$ & $64.3 \pm 18.8^{*}$ & $68 \pm 18.9 *$ & $76.5 \pm 13.1$ \\
$\begin{array}{l}\text { Overweight \& } \\
\text { Obese }\end{array}$ & $70.6 \pm 17.3$ & $64 \pm 19 *$ & $62.4 \pm 18.9 * *$ & $67.6 \pm 18.3^{*}$ & $71.7 \pm 12.1$ \\
\hline
\end{tabular}

Table 4: Means and Standard Deviations of academic achievements for all Groups.

* $P<0.05$, ** $P<0.01$ 
unit, the math score decreased by 3. The results of linear regression for science score indicated that healthy intake, physical activity, and their interaction were significant predictors of science score $(F(6,1938)=14.6, p<.01)$, with an $R 2$ of 0.043 . The healthy intake, physical activity, healthy intake and physical activity, SES, age and sex were significant predictors of science score $(\mathrm{HI}, \mathrm{t}=2.6$ $p<0.01, \mathrm{PA}, \mathrm{t}=3.5, p<0.05,[\mathrm{HI} \times \mathrm{PA}], \mathrm{t}=2.5, p<0.05$, SES, $\mathrm{t}=5.7, p<0.01$, Age, $\mathrm{t}=-3.9, p<0.01$, Sex, $\mathrm{t}=2$, $p<0.01)$. In addition, the prediction equation for science score (Yscience $=59.6+3.1 \mathrm{HI}+1.7 \mathrm{PA}+4.7[\mathrm{HI}$ $x$ PA]+3.7 SES-2.0 age+1.6sex) indicates the following for significant predictors: (1) As healthy intake increased by one unit, the science score increased by 3.1, (2) as physical activity increased

Table 5: Linear Regression of Arabic and English languages scores.

\begin{tabular}{|c|c|c|c|c|c|c|}
\hline & \multicolumn{3}{|c|}{ Arabic Language } & \multicolumn{3}{|c|}{ English Language } \\
\hline & B & $\mathrm{t}$ & $95 \% \mathrm{Cl}$ & $B$ & $\mathrm{t}$ & $95 \% \mathrm{Cl}$ \\
\hline $\begin{array}{l}\text { Healthy } \\
\text { Intake }\end{array}$ & 3.3 & $2.8^{* \star}$ & $\begin{array}{c}(-5.18- \\
1.83)\end{array}$ & 3.3 & $2.6^{* *}$ & $(-4.93-2.69)$ \\
\hline $\begin{array}{l}\text { Physical } \\
\text { Activity }\end{array}$ & 1.5 & $3.2^{\star \star}$ & $(0.6-2.44)$ & 1.7 & $3.3^{* *}$ & $(0.69-2.69)$ \\
\hline $\begin{array}{l}\text { Healthy } \\
\text { and } \\
\text { Active }\end{array}$ & 4.5 & $2.5^{\star}$ & $(1-8)$ & 4.2 & $2.2^{*}$ & $(0.39-7.99)$ \\
\hline SES & 3.6 & $5.9^{* *}$ & $(2.44-4.85)$ & 3.9 & $5.9^{\star \star}$ & $(2.64-5.26)$ \\
\hline Age & -2.8 & $-5.6^{\star \star}$ & $(-3.79-1.83)$ & -2.9 & $-5.3^{\star \star}$ & $(-3.94--1.81)$ \\
\hline Sex & 3.3 & $4.2^{\star \star}$ & $(1.77-4.84)$ & 3.2 & $3.8^{\star \star}$ & $(1.54-4.88)$ \\
\hline
\end{tabular}

* $P<0.05$, ** $P<0.01$ by 1 unit, the science score increased by 1.7, (3) as the interaction between healthy intake and physical activity increased by 1 unit the science score increased by 4.7, (4) as the SES increased by 1 unit, the science score increased by 3.7, (5) as age increased by 1 unit, the science score decreased by 2.0 (6) sex influenced the science score with girls scoring higher by 1.6 than boys.

The results of linear regression for total average score indicated that healthy intake, physical activity, and their interaction were significant predictors of total average score $(F(6,1938)=16.2$, $p<.01$ ), with an R2 of 0.045 . The healthy intake, physical activity, healthy intake and physical activity, SES, age and sex were significant predictors of total average score ( $\mathrm{HI}, \mathrm{t}=2.7 p<0.01, \mathrm{PA}, \mathrm{t}=3.5$, $p<0.05,[\mathrm{HI} \times \mathrm{PA}], \mathrm{t}=2.0, p<0.05, \mathrm{SES}, \mathrm{t}=6.6, p<0.01$, Age, $\mathrm{t}=-4.0, p<0.01$, Sex, $\mathrm{t}=2.5, p<0.05)$.In addition, the prediction equation for total average score (Ytotal Average $=66.2+2.4 \mathrm{HI}+1.3 \mathrm{PA}+2.8[\mathrm{HI} \times \mathrm{PA}]+3.2$ SES-1.5 age+1.6 sex) indicates the following for significant predictors: (1) As healthy intake increased by one unit, the total average score increased by 2.4, (2) as physical activity increased by 1 unit, the total average score increased by 1.3, (3) as the interaction between healthy intake and physical activity increased by 1 unit the total average score increased by 2.8, (4) as the SES increased by 1 unit, the total average score increased by 3.2 (5) as age increased by 1 unit, the total average score decreased by 1.5 (6) sex influenced the total average score with girls scoring

Table 6: Linear Regression of math, science and total average scores

\begin{tabular}{|c|c|c|c|c|c|c|c|c|c|}
\hline & \multicolumn{3}{|c|}{ Math } & \multicolumn{3}{|c|}{ Science } & \multicolumn{3}{|c|}{ Total average score } \\
\hline & B & $\mathrm{t}$ & $95 \% \mathrm{Cl}$ & B & $\mathrm{t}$ & $95 \% \mathrm{Cl}$ & $B$ & $\mathrm{t}$ & $95 \% \mathrm{Cl}$ \\
\hline $\begin{array}{l}\text { Healthy } \\
\text { Intake }\end{array}$ & 2.2 & $1.7^{*}$ & $(-5.43-2.22)$ & 3.1 & $2.6^{\star \star}$ & $(-5.21-2.13)$ & 2.4 & $2.7^{\star \star}$ & $(-3.61-1.86)$ \\
\hline $\begin{array}{l}\text { Physical } \\
\text { Activity }\end{array}$ & 1.4 & $2.8^{\star}$ & $(0.41-2.41)$ & 1.7 & $3.5^{*}$ & $(0.75-2.67)$ & 1.3 & $3.5^{\star}$ & $(0.57-2.01)$ \\
\hline $\begin{array}{l}\text { Healthy and } \\
\text { Active }\end{array}$ & 3.2 & 1.7 & $(-0.59-7.05)$ & 4.7 & $2.5^{\star}$ & $(1.08-8.41)$ & 2.8 & $2.0^{*}$ & $(0.12-5.57)$ \\
\hline SES & 3.9 & $5.8^{\star \star}$ & $(2.54-5.17)$ & 3.7 & $5.7^{\star \star}$ & $(2.44-4.96)$ & 3.2 & $6.6^{* \star}$ & $(2.23-4.1)$ \\
\hline Age & -3.0 & $-5.5^{\star \star}$ & $(-4.08--1.95)$ & -2.0 & $-3.9^{\star \star}$ & $(-3.07--1.02)$ & -1.5 & $-4.0^{\star *}$ & $(-2.31--0.79)$ \\
\hline Sex & 1.3 & 1.5 & $(-0.41-2.94)$ & 1.6 & $2.0^{*}$ & $(0.02-3.24)$ & 1.6 & $2.5^{\star}$ & $(0.36-2.75)$ \\
\hline
\end{tabular}


higher by 1.6 than boys. Table 7 presents the linear regression analysis of negative health behaviors with the students' total average score. The results indicated that unhealthy intake (UI), non-active (NA), the interaction between unhealthy intake and non-active (UINA), and the overweight and obese (00) were significant predictors of total average score $(F(7,1937)=14, p<.01)$, with an R2 of 0.05 . Unhealthy intake, non-active, unhealthy intake and non-active, overweight and obese, SES, age and sex were significant negative predictors of total average score (UI, $\mathrm{t}=-3.0 p<0.01, \mathrm{NA}, \mathrm{t}=-$ 2.1, $p<0.01$, [UI $x \mathrm{NA}$ ], $\mathrm{t}=-2.3, p<0.01,00 \mathrm{t}=-3.2$, $p<0.01$, SES $\mathrm{t}=6, p<0.01$, Age, $\mathrm{t}=-4.0, p<0.01$, Sex, $\mathrm{t}=2.9, p<0.01)$. In addition, the prediction equation for total average score (Ytotal average $=72-$ 1.9UI-2NA-2[UIxNA]-300+3.1SES-1.7age+1.9sex) indicates the following for significant predictors: (1) As unhealthy intake increased by one unit, the total average score decreased by 1.9, (2) as nonphysical activity increased by 1 unit, the total average score decreased by 2, (3) as the interaction between unhealthy intake and nonphysical activity increased by 1 unit the total average score decreased by 2, (4) as the overweight and obesity increased by 1 unit, the total average score decreased by 3, (5) the SES increased by 1 unit, the total average score increased by 3.1 (5) as age increased by 1 unit, the total average score decreased by 1.7 (6) sex influenced the total average score with boys scoring higher by 1.9 than girls.

Table 7: Linear Regression of unhealthy lifestyle and total average score

\begin{tabular}{lccc}
\hline & \multicolumn{3}{c}{ Total average score } \\
& $\mathrm{B}$ & $\mathrm{t}$ & $95 \% \mathrm{CI}$ \\
\hline Unhealthy Intake & -1.9 & $-3^{\star \star}$ & $-3.2--0.7$ \\
Non-Active & -2 & $-2.1^{\star \star}$ & $-3.9--0.1$ \\
Unhealthy \& non-active & -2 & $-2.3^{\star \star}$ & $-3.6--0.3$ \\
Overweight \& Obese & -3 & $-3.2^{\star \star}$ & $-4.8--1.1$ \\
SES & 3.1 & $6^{\star *}$ & $2.1-4.1$ \\
Age & -1.7 & $-4^{\star \star}$ & $-2.5--0.9$ \\
Sex & 1.9 & $2.9^{\star *}$ & $0.6-3.2$ \\
\hline
\end{tabular}

${ }^{*} P<0.05,{ }^{*} P<0.01$

\section{Discussion}

Our study aimed to identify the links between healthy food consumption and regular physical activity and to identify the significant effect on students' academic achievement among Palestinian schoolchildren. It has been identified that normal level of physical activity and proper nutrition have a significant effect on students' growth, cognitive development and academic achievement. Moreover, it has been found that overweight and obesity have a negative impact on students' mental health and cognitive development. However, in Palestine, few studies assessed the effect of physical activity and proper nutrition on students' cognitive development and academic achievement (Abudayya et al. 2011). To the best of our knowledge, no other studies have examined the association between health behaviors and academic achievement on a national survey among schoolchildren in West Bank. The study demonstrated a strong association between proper food intake and regular physical activity and academic achievement among students in grades 5-9 in the West Bank. Healthy food consumers and physically active students reported a strong association with high academic achievement, which remains highly significant after adjustment with socioeconomic status, age, and sex. The study also shows a negative association between overweight and obesity and sedentary behaviors with academic achievements. This study showed not only proper nutrition and regular physical activity have an association with academic achievement, but also the interaction between healthy food intake, physical activity, parents' education, and socioeconomic status had a strong association with academic achievement.

Our findings recommend that healthy food intake and adequate physical activity may positively affect academic achievement scores. The regression analysis results showed that students who consumed healthy food intake 
(fruits and vegetables) had higher scores than students who consumed unhealthy food intake (soft drinks, chocolates, and energy drinks) in the Arabic language, English language, math, science, and the total average score. Furthermore, results showed that students with a high physical activity level reported higher scores than non-active students in all selected courses and the overall average score. On the other hand, unhealthy food consumers, non-active, and overweight and obese students reported lower academic achievement scores in Arabic, English, math, science, and the overall average score. The categorization of food intake, physical activity into healthy and unhealthy food intake, and active and sedentary lifestyle behaviors are consistent with other similar studies (Ramirez and Meyer 2006; Rampersaud et al. 2005; Stea and Torstveit 2014; Bleiweiss-sande et al., 2019; Abudayya et al. 2011). The categorization of academic achievement scores was consistent with the literature (Stea and Torstveit 2014). The study is in accordance with other previously published studies, which have reported the association between nutrition, physical activity, and academic achievement. Some studies focused on meal patterns and academic achievement and focused on the importance of breakfast and the regularity of meal patterns throughout the day (Rathi, Riddell, and Worsley 2017; Montazerifar, Karajibani, and Dashipour 2012; Vadiveloo, Zhu, and Quatromoni 2009; Bleiweiss-sande et al., 2019).

To best to our knowledge, no other studies examined the relationship between specific food intake and academic achievement among schoolchildren in West Bank. Results from our study showed increased odds of high academic achievement in boys and girls who had a higher intake of fruits and vegetables. In contrast, the results showed a decreased odds of high academic achievement in boys and girls who had a high intake of soft-drink, sugar, and energy drink. The study results are consistent with other similar studies that reported increased odds of high academic scores in student who had high fruit and vegetable consumption (Hou et al. 2020; Kristo et al. 2020; Bleiweiss-sande et al., 2019). Our study results are also consistent with other studies that reported that high consumption of salty snacks and soft-drinks is associated with low academic achievement. However, the study is inconsistent with other studies which reported lower odds of academic scores for girls with high sweet and chocolate consumption (Asigbee et al., 2018; Kim et al., 2003; Castelli et al., 2015; Vadiveloo, Zhu, and Quatromoni 2009; Stea and Torstveit 2014). Other studies reported that lower intake of fruits and vegetables and a high intake of sweets, soft drinks and energy drinks was associated with lower math score (Vadiveloo, Zhu, and Quatromoni 2009; Rampersaud et al. 2005; Rathi, Riddell, and Worsley 2017; S. Y. Kim et al. 2016; Stea and Torstveit 2014; Abudayya et al. 2011). Our study also examined the effect of physical activity and leisure time activities on academic achievement scores. The results showed a positive association between high physical activity, lower leisure time activity, and academic achievement in both boys and girls. The results are consistent with other studies that revealed a positive association with academic achievement (Ruiz et al. 2010; Rodríguez García et al. 2014; Armstrong and Welsman 2006; Moral-García et al. 2020; Hou et al. 2020; Janssen 2012; Stea and Torstveit 2014; Taras 2005). The Spanish and Norwegian studies reported that the high academic score had a significant association with physical activity and leisure time activity (Stea and Torstveit 2014; Rodríguez García et al. 2014). Our results reported that physical activity was positively associated with academic achievement in boys, and the leisure time activity was positively associated with academic achievements in girls, which is consistent with multiple studies (Desai et al. 2015; Taras 2005; Asigbee et al., 2018). The sex-specific association might be explained by the differences in the interest of boys and girls in physical activity, and also might be due to cultural issues and the lim- 
ited available after school activities for girls. The linear regression analysis examined the effect of food intake, physical activity, and the interaction between food intake and physical activity on the academic achievement score of the Arabic language, English language, math, science, and the total average score.

The results showed a significant association between healthy intake and physical activity and the academic achievement, for example, for math achievement scores, healthy intake increased the academic scores by 2.2, the physical activity increased the academic scores by 1.4 , and the interaction between health intake and physical activity increased the academic scores by 3.2. The study result is in accordance with another study that showed a significant increase in academic achievement scores of reading, math, and science scores with the increase of healthy nutrition and physical activity (Janssen 2012; Stea and Torstveit 2014; Asigbee el al., 2018). On the other hand, the linear regression analysis examined the effect of unhealthy behaviors on the students' overall average academic score. The results showed that if unhealthy food consumption increased by one unit the scores decreased by 1.9 , and the decrease in physical activity by one unit will decrease the scores by 2 , the interaction between unhealthy and low physical activity increase by one unit the scores will decrease by 2 , and the increase of overweight and obesity by one unit will decrease the academic scores by 3 , the results are in accordance with other previous studies (Asigbee et al., 2018). Furthermore, the results of this study are mostly in line with the results from previous studies that examined the effect of health behaviors on academic scores among schoolchildren (Stea and Torstveit 2014; Moral-García et al. 2020; Kim et al., 2003; Kristo et al. 2020; Faught et al., 2017). There are some limitations to the present study. First, our findings were limited to the West Bank population and don't include students from Gaza. Our results would be strengthened by studying a homogeneous national sample from all Palestinian cities.

Second, the study did not examine the eating habits and meal patterns throughout the day time and doesn't include the breakfast pattern. However, the study strengthened by examining specific food intake, the variety of physical activities, and leisure time activities. Another possible limitation, that the self-reported nature of health behaviors can be prone to bias. Despite these limitations, our study is strengthened by using a representative weighted sample of the West Bank population and conducted by welltrained research assistants under the direct supervision of the school health behavior department at the Ministry of Education.

\section{Conclusion}

In conclusion, the results of the present study indicated that the academic achievement of Palestinian schoolchildren was strongly associated with regular physical activity and healthy food intake. The average consumption of fruits and vegetables and the average level of physical activity are relatively important for improving students' academic achievement scores. Lower academic scores were found among students with low physical activity rates, high unhealthy food intake, and obesity.

Based on the study finding, future intervention studies should investigate the combined effect of nutrition and healthy lifestyle, on cognitive development and academic achievement. Furthermore, the study supports the implementation of a school health behavior program that promotes a healthy lifestyle which may lead to better academic achievement. Specifically, school educators may consider developing new courses that will improve students' knowledge of adopting a healthy lifestyle.

\section{Sources of funding}

The analysis presented in this paper is part of the wider project "Determinants of Cog- 
nitive Development in Deprived Environments: Evidence from the West Bank" funded by the German Research Foundation (DFG) under grant number JU 2769/2.

\section{Sponsor's role}

Collaboration on research hypotheses development and manuscript preparation. Conflicts of Interest: The authors declare no conflict of interest. The funders had no role in the design of the study; in the collection, analyses, or interpretation of data; in the writing of the manuscript; or in the decision to publish the results.

\section{Ethics declaration}

The study received ethical approval from the Ministry of Education and the Al-Quds University Institutional Review Board (IRB). Parental consent approval to participate in the survey was obtained from all participants. The data were collected, entered, and cleaned by trained research assistants under the supervision of the Ministry of Education and Al-Quds Nutrition and Health research institute (ANAHRI) at Al-Quds University.

\section{Sources of Support}

German Research Foundation (DFG) under grant number JU 2769/2.

\section{Acknowledgments}

The authors wish to thank the Ministry of Education, Palestine for permitting us to conduct the study, the children and their parents for their patience and all field workers. Authors wish to thank Mohammad Remawi and Suzan Tutah for their support in data collection and we are also grateful to Sameh Al Halaq for his contributions.

\section{References}

Abudayya, A., Z. Shi, Y. Abed, and G. Holmboe Ot tesen. 2011. "Diet, Nutritional Status and School Performance $t$ among Adolescents in Gaza
Strip.” Eastern Mediterranean Health Journal 17 (03): 218-25. https://doi.org/10.26719/2011.17.3.218. Adolphus, Katie, Clare L. Lawton, and Louise Dye. 2013. "The Effects of Breakfast on Behaviour and Academic Performance in Children and Adolescents." Frontiers in Human Neuroscience, no. JUL. https://doi.org/10.3389/fnhum.2013.00425.

Alhilabi, Hanan S, and Anne Payne. 2018. "The Im pact of Skipping Breakfast on the Body Weight of Children and Young People in Saudi Arabia: A Systematic Review" 3 (3): 67-104. https://doi. org/10.18502/ajne.v3i3.3588.

Armstrong, Neil, and Joanne R. Welsman. 2006.

"The Physical Activity Patterns of European Youth with Reference to Methods of Assessment.” Sports Medicine 36 (12): 1067-86. https:// doi.org/10.2165/00007256-200636120-00005.

Asigbee, FM., Whitney, SD., andPeterson, C. E. 2018. "The Link Between Nutrition and Physical Activity in Increasing Academic Achievement." The Journal of school health, 88(6), 407-415. https:// doi.org/10.1111/josh.12625

Asmare, Biachew, Mekuanint Taddele, Sileshi Berihun, and Fasil Wagnew. 2018. "Nutritional Status and Correlation with Academic Performance among Primary School Children, Northwest Ethiopia.” BMC Research Notes, 1-6. https://doi.org/10.1186/s13104-018-3909-1.

Banerjee, Pallavi Amitava. 2016. "A Systematic Re view of Factors Linked to Poor Academic Performance of Disadvantaged Students in Science and Maths in Schools." Cogent Education 3 (1): 1-17. https://doi.org/10.1080/233118 6X.2016.1178441.

Bleiweiss-sande, Rachel, Kenneth Chui, Cath erine Wright, Stephanie Anzman-frasca, Sarah Amin, and Jennifer Sacheck. 2019 "Associations Between Dietary Intake Patterns, Cognition and Academic Achievement in 3rd and 4th Grade Children from the Fueling Learning Through Exercise Study (P04-096-19)," 287-89.

Burkhalter, Toni M, and Charles H Hillman. 2011. "Forum on Child Obesity Interventions A Narrative Review of Physical Activity, Nutrition, and Obesity to Cognition and Scholastic Performance across the Human Lifespan 1 - 3." An International Review Journal 2.2: 201-6. https:// doi.org/10.3945/an.111.000331.and.

Burrows, T., S. Goldman, K. Pursey, and R. Lim. 2017. "Is There an Association between Dietary Intake and Academic Achievement: A Systematic Review." Journal of Human Nutrition and Dietetics 30 (2): 117-40. https://doi.org/10.1111/ 
jhn.12407.

Castelli, Glowacki, Barcelona, Calvert and Hwang.2015."Growing Evidence on Physical Activity and Academic Performance."Available at www.activelivingresearch.org.

Cook, H.D. and Kohl III, H.W. eds., 2013. Educating the student body: Taking physical activity and physical education to school.Washington, DC: The National Academies Press. https://doi. org/10.17226/18314.

Desai, Ishaan K, Anura V Kurpad, Virginia R Chomitz, and Tinku Thomas. 2015. "Aerobic Fitness, Micronutrient Status, and Academic Achievement in Indian School-Aged Children,"1-13.https://doi. org/10.1371/journal.pone.0122487.

Florence MD, Asbridge M, Veugelers PJ. Diet quality and academic performance.J Sch Health. 2008; 78: 209-215

Dubuc, Marie Maude, Mylène Aubertin-Leheudre, and Antony D. Karelis. 2020. "Lifestyle Habits Predict Academic Performance in High School Students: The Adolescent Student Academic Performance Longitudinal Study (ASAP).” International Journal of Environmental Research and Public Health 17 (1): 1-15. https://doi.org/10.3390/ ijerph17010243.

Faught, Erin L., John P. Ekwaru, Douglas Gleddie, Kate E. Storey, Mark Asbridge, and Paul J. Veugelers. 2017. "The Combined Impact of Diet, Physical Activity, Sleep and Screen Time on Academic Achievement: A Prospective Study of Elementary School Students in Nova Scotia, Canada." International Journal of Behavioral Nutrition and Physical Activity 14 (1): 1-13. https://doi.org/10.1186/s12966-017-0476-0.

Forrest, Christopher B., Katherine B. Bevans, Anne W. Riley, Richard Crespo, and Thomas A. Louis. 2013. "Health and School Outcomes during Children's Transition into Adolescence." Journal of Adolescent Health 52 (2): 186-94. https://doi.org/10.1016/j.jadohealth.2012.06.019.

Frank, G C, T A Nicklas, L S Webber, C Major, J F Miller, and G S Berenson. 1992. "A Food Frequency Questionnaire for Adolescents: Defining Eating Patterns." Journal of the American Dietetic Association 92 (3): 313-18.

Hou, Yujiao, Guang Mei, Yutong Liu, and Weisheng

Xu. 2020. "Physical Fitness with Regular Lifestyle Is Positively Related to Academic Performance among Chinese Medical and Dental Students." BioMed Research International 2020 (1). https://doi.org/10.1155/2020/5602395.

Janssen, I. 2012. "Physical Activity and Perfor mance at School: A Systematic Review of the Literature Including a Methodological Quality Assessment." Yearbook of Sports Medicine 2012: 357-58. https://doi.org/10.1016/j. yspm.2012.03.025.

Jeong, Eun-young. 2019. “The Influence of Break fast on the Academic Performance of SchoolAge Adolescents : Systematic Review *" 52 (2).

Kim, Hye Young P., Edward A. Frongillo, Sung Sook Han, Se Young Oh, Woo Kyung Kim, Young Ai Jang, Hye Sook Won, Hyun Sook Lee, and Sook He Kim. 2003. "Academic Performance of Korean Children Is Associated with Dietary Behaviours and Physical Status." Asia Pacific Journal of Clinical Nutrition 12 (2): 186-92.

Kim, So Young, Songyong Sim, Bumjung Park, Il Gyu Kong, Jin Hwan Kim, and Hyo Geun Choi. 2016. "Dietary Habits Are Associated with School Performance in Adolescents." Medicine (United States) 95 (12): 1-10. https://doi.org/10.1097/ MD.0000000000003096.

Kristo, Aleksandra S., Büșra Gültekin, Merve Özta, and Angelos K. Sikalidis. 2020. "The Effect of Eating Habits' Quality on Scholastic Performance in Turkish Adolescents." Behavioral Sciences 10 (1): 1-17. https://doi.org/10.3390/bs10010031.

Lundqvist, Martina, and Nicklas Ennab Vogel. 2019. “In Economic Evaluations" 1: 1-15.

Marques, Adilson, Francisco Gómez, João Martins, Ri cardo Catunda, and Hugo Sarmento. 2017. "Association between PE, School-Based PA, and Academic Performance. A Systematic Review." Retos 2041: 316-20.

Montazerifar, Farzaneh, Mansour Karajibani, and Ali Reza Dashipour. 2012. “Evaluation of Dietary Intake and Food Patterns of Adolescent Girls in Sistan and Baluchistan Province, Iran.” Functional Foods in Health and Disease 2 (3): 62. https://doi.org/10.31989/ffhd.v2i3.98.

Moral-García, José Enrique, José David Urchaga-Lita go, Antonio Jesús Ramos-Morcillo, and Rubén Maneiro. 2020. "Relationship of Parental Support on Healthy Habits, School Motivations and Academic Performance in Adolescents." International Journal of Environmental Research and Public Health 17 (3). https://doi.org/10.3390/ ijerph17030882.

Pavleski, Daniel, Daniela Koltovska-Nechoska, and Edouard Ivanjko. 2017. "Evaluation of Adaptive Traffic Control System UTOPIA Using Microscopic Simulation." Proceedings Elmar - International Symposium Electronics in Marine 2017-Septe (10): 17-20. https://doi.org/10.23919/ 
ELMAR.2017.8124425.

Ramirez, Francisco 0, and John W Meyer. 2006. "Stu dent Achievement and National Economic Growth" 113 (November): 1-29.

Rampersaud, Gail C., Mark A. Pereira, Beverly L. Girard, Judi Adams, and Jordan D. Metzl. 2005. "Breakfast Habits, Nutritional Status, Body Weight, and Academic Performance in Children and Adolescents." Journal of the American Dietetic Association 105 (5): 743-60. https://doi. org/10.1016/j.jada.2005.02.007.

Rathi, Neha, Lynn Riddell, and Anthony Worsley. 2017. "Food Consumption Patterns of Adolescents Aged 14-16 Years in Kolkata, India." Nutrition Journal 16 (1): 1-12. https://doi.org/10.1186/ s12937-017-0272-3.

Roberts, Chris, Candace Currie, Oddrun Samdal, Dor othy Currie, Rebecca Smith, and Lea Maes. 2007. "Measuring the Health and Health Behaviours of Adolescents through Cross-National Survey Research: Recent Developments in the Health Behaviour in School-Aged Children (HBSC) Study." Journal of Public Health 15 (3): 179-86. https://doi.org/10.1007/s10389-007-0100-x.

Rodríguez García, Pedro Luis, Francisco José López Vil lalba, Pedro Ángel López Miñarro, and Eliseo
García Cantó. 2014. “Physical Exercise, Energy Expen diture and Tobacco Consumption in Adolescents from Murcia (Spain)." Archivos Argentinos de Pediatria 112 (1): 12-18. https://doi.org/10.5546/ aap.2014.e12.

Ruiz, Jonatan R., Francisco B. Ortega, Ruth Castillo, Miguel Martín-Matillas, Lydia Kwak, German Vicente-Rodríguez, Jose Noriega, Pablo Tercedor, Michael Sjöström, and Luis A. Moreno. 2010. "Physical Activity, Fitness, Weight Status, and Cognitive Performance in Adolescents." Journal of Pediatrics 157 (6). https://doi.org/10.1016/j. jpeds.2010.06.026.

Stea, Tonje H., and Monica K. Torstveit. 2014. “Asso ciation of Lifestyle Habits and Academic Achievement in Norwegian Adolescents: A Cross-Sectional Study." BMC Public Health 14 (1): 1-8. https://doi.org/10.1186/1471-2458-14-829.

Taras, Howard. 2005. "Physical Activity and Student Performance at School." Journal of School Health 75 (6): 214-18. https://doi. org/10.1111/j.1746-1561.2005.tb06675.x.

Vadiveloo, Maya, Lei Zhu, and Paula A. Quatromoni. 2009. "Diet and Physical Activity Patterns of School-Aged Children." Journal of the American Dietetic Association 109 (1): 145-51. https://doi. org/10.1016/j.jada.2008.10.012. 